\title{
The Relationship Between Perceived Social Support and Lifestyle in Middle-Aged Females of Ahvaz, Iran
}

\author{
Nahid Javadifar, ${ }^{1}$ Atefeh Larki, ${ }^{2,}{ }^{*}$ Mojgan Javadnoori, ${ }^{1}$ and Mohamad Hosein Haghighizadeh ${ }^{3}$ \\ ${ }^{1}$ Reproductive Health Promotion Research Centre, Ahvaz Jundishapur University of Medical Sciences, Ahvaz, IR Iran \\ ${ }^{2}$ Department of Nursing and Midwifery, Ahvaz Jundishapur University of Medical Sciences, Ahvaz, IR Iran \\ ${ }^{3}$ Health School, Ahvaz Jundishapur University of Medical Sciences, Ahvaz, IR Iran \\ "Corresponding author: Atefeh Larki, Department of Nursing and Midwifery, Ahvaz Jundishapur University of Medical Sciences, Ahvaz, IR Iran, E-mail: atefeh.larki@gmail.com
}

Received 2016 February 14; Revised 2016 May 28; Accepted 2016 July 04.

\begin{abstract}
Background: Females' health is the growth indicator of countries. To maintain and promote health is essential to correct and improve lifestyle. Objectives: Accordingly, the current study aimed to determine the relationship between social support and life style.

Methods: In this cross-sectional study, 700 middle-aged females were selected by random multistage cluster sampling method in Ahvaz, Iran. The data were collected using demographic questionnaire, the personal resource questionnaire (PRQ 85- Part II perceived social support) and lifestyle questionnaire (LSQ). Data were analyzed by the Spearman correlation coefficient, ANOVA and linear regression.

Results: Results showed significant association between total score of perceived social support and lifestyle $(\mathrm{P}>0.001)$. Regression results showed a significant relationship among the variables; only variables of perceived social support, economic status, health status, family structure and education of husband were significantly associated with lifestyle $(\mathrm{P}<0.05)$. Also total score of social support and the dimensions had a direct and positive correlation with lifestyle.

Conclusions: Perceived social support has a strong and positive association with lifestyle; interventions of social support should be considered in programs to improve lifestyle in such females.
\end{abstract}

Keywords: Social Support, Lifestyle, Middle Age

\section{Background}

Females are as pillars of social development and the basis of family; they have important roles in the family and society. It is required that they have physical and mental health $(1,2)$. The world health organization introduced females' health as the growth indices of countries (3). Middle age is to the time for physical, mental, social and family dimension changes in females' lives (4). Population of 40 - 65-year-old females in Iran is more than 4.5 million (5). These courses of life, due to increased life expectancy, constitute the largest part of adults' lives. The golden age of females' lives is their childbearing age (6). Therefore, increasing attention to the issue of females' health is essential in this period of life.

One of the social determinants of health that refers to the importance of the social dimension is social support; the evidence is increasing for protective effects of social support on health outcomes. However, an important question, that is not clearly answered yet, is its directions and mechanisms (7). Social support is generally divided into two categories, the real social support that is the support people receive; the second batch including perceived or mental social support; the subjective sense of belonging, acceptance, recognition and assistance conditions is required (8). Social support is associated with multiple psycho-social benefits such as improved self-esteem, a sense of empowerment, improving health and higher quality of life and the lack of it is associated with lose of mental protests, stress and low level of health (9). Social support may be associated with factors that play a role in people's health or affect them (10). Lifestyle is among the factors that can have positive or negative impacts on health. Health requires promotion of lifestyle. To maintain and improve health, it is essential to correct and improve the lifestyle (11). The world health organization (WHO) believes that change and modification of lifestyle can cause many risk factors that are among the most important causes of death (12). Therefore, based on studies by Tamakoshi et al. (13) in Japan, lifestyle management could prevent $18.5 \%$ of deaths in females. On the other hand, each of lifestyle factors is independently and significantly predictive of multiple chronic diseases and mortality in middle-aged females (14). Since social attitudes toward health and factors affecting it has changed; today, many researchers instead of addressing the treatment of diseases insist on prevention. The role of lifestyle is obvious in a healthy life and prevention of diseases of different ages. Several factors are affecting the lifestyle of females of different ages. It seems that possible factors related to lifestyle are not reviewed, in particular little attention is paid to the issue of social support in such females, and studies in this field are limited.

\section{Objectives}

Considering the lack of studies in this field in Iran, to evaluate the relationship between social support and 
lifestyle in middle-aged females can help to develop and design health promotion and prevention programs in this age group.

\section{Methods}

It was a descriptive, cross-sectional analytical study. Sampling was conducted in Ahvaz health centers, Ahvaz, Iran. One health center was randomly selected from each of the eight Ahvaz municipal areas; proportional to the population covered by each health center and the number of family files, sampling was done in the eight centers. The final sample consisted of 700 middle aged females of 40 60 years old who were literate.

Data collection instruments included demographicsocial characteristics (age, husband's age, marital status, economic status, education, spouse's education, ethnicity, health status, family structure and dimension, and resource of initial support), perceived social support and lifestyle questionnaires. For this purpose, the second part of the personal resource questionnaire (PRQ 85 - Part II perceived social support) was used. To measure social support, PRQ- 85 was designed by Brandt and Weinert in 1987. It includes 25 items in five dimensions (individual worth, social integration, assistance, nurturance and assistance). Cronbach's alpha and intra-class correlation coefficients were 0.84 and 0.9 , respectively (15). The validity and reliability of the Persian version of this questionnaire was confirmed by Rambod and Rafiee. Cronbach's alpha of the PRQ 85-Part II was 0.85 in the current study. Questionnaire score was in the range of $25-175$ for the whole questionnaire and 5 - 35 for each dimension. Obtained scores were classified in three levels of support; that is high, moderate and low. Scores of 25 - 75 were classified as low perceived social support, scores of 76 - 125 as average and 126 - 175 as high (16). Lifestyle questionnaire (LSQ) was designed by Lali et al. (17) In the current study, the indices of Cronbach's alpha and intraclass correlation coefficient for LSQ were 0.87 and 0.81 , respectively, the scientific reliability of this questionnaire was obtain by test re-test method. The questionnaire has 70 items and its objective is to evaluate the different aspects of lifestyle such as physical health, exercise and fitness, weight management and nutrition, disease prevention, psychological health, spiritual health, social health, avoid drugs and drug consumption, accident prevention and environmental health. Questionnaire scores are in the range of 70 - 210 for the whole questionnaire and for its dimensions are 6 - 48. To collect data, ethical code (No. U 94033) was obtained from Ahvaz Jundishapur University of Medical Sciences. The principal researcher introduced herself and the study objectives to the participants. Interview was conducted after giving confidence to maintain confidentiality for answers and obtaining consent of the participants.

Data were analyzed using SPSS version 22. To evaluate social demographic features, descriptive statistics was used; Spearman correlation coefficient and ANOVA were used to determine the relationship between perceived social supports and lifestyle; to determine the effect of confounding variables on the lifestyle, linear regression was used.

Table 2. The Relationship Between Perceived Social Support and Lifestyle

\begin{tabular}{l|c|c|c}
\hline $\begin{array}{l}\text { Types of } \\
\text { Perceived } \\
\text { Social Support }\end{array}$ & Frequency (\%) & $\begin{array}{c}\text { Mean } \pm \text { S D for } \\
\text { Lifestyle }\end{array}$ & PValue $^{\mathbf{a}}$ \\
\cline { 1 - 2 } Low & $29(4.1)$ & $121.55 \pm 23.43$ & \multirow{2}{*}{0} \\
\hline Moderate & $436(62.3)$ & $139.38 \pm 20.77$ & \multirow{2}{*}{0} \\
\hline High & $235(33.6)$ & $172.58 \pm 26.31$ & \\
\hline Total & $700(100)$ & $149.78 \pm 26.31$ & \\
\hline
\end{tabular}

${ }^{\mathrm{a}} \mathrm{P}<0.05$ was considered as level of significance (2-tailed).

\section{Results}

Results of ANOVA showed significant association between perceived social support and lifestyle $(\mathrm{P}>0.001)$ (Table 2).

In Table 3, the variables of marital status, education, job, education and husband's job, economic status, family structure, health status, the primary supporter and perceived social support were transferred to the multivariable linear regression model. The study found five statistically significant variables that influenced lifestyle behaviors: perceived social support, economic status, health status, family structure and husband's education $(\mathrm{P}<0.05)$. Overall, these variables predicted $74 \%$ of lifestyle behaviors changes $\left(R^{2}=0.746\right)$.

Table 4 showed that perceived social support and also its dimensions, including those of individual worth, social integration, intimacy, nurturance and assistance had direct and positive significant relationship with lifestyle $(\mathrm{P}<$ 0.05). The highest correlation was between total social support and lifestyle $(r=0.748)$. At sub-scales of level of social support, the dimension of intimacy had the highest correlation with life style $(r=0.684)$. And social integration dimension had the lowest correlation $(r=0.506)$.

\section{Discussion}

The results of the current study showed significant association between perceived social supports and lifestyle. 
Table 3. Regression Analysis of Factors Associated With Lifestyle

\begin{tabular}{|c|c|c|c|c|c|}
\hline Variables & $\beta$ & PValue $^{\mathrm{a}}$ & $\mathbf{T}$ & Adjusted $\mathbf{R}^{2}$ & $\mathbf{R}^{2}$ \\
\hline Perceived social support & 1.567 & 0 & 22.352 & \multirow{5}{*}{0.552} & \multirow{5}{*}{0.746} \\
\hline Economic status & 5.917 & 0.026 & 2.234 & & \\
\hline Health status & -5.040 & 0.003 & -2.994 & & \\
\hline Family structure & -8.938 & 0.018 & -2.374 & & \\
\hline Education of husband & 4.815 & 0.049 & 1.969 & & \\
\hline
\end{tabular}

Table 4. Correlation Between Perceived Social Support and Lifestyle

\begin{tabular}{|c|c|}
\hline Variables & Correlation (r): Lifestyle $^{a}$ \\
\hline Individual worth & 0.590 \\
\hline Social integration & 0.506 \\
\hline Intimacy & 0.684 \\
\hline Nurturance & 0.680 \\
\hline Assistance & 0.666 \\
\hline Perceived social support & 0.748 \\
\hline
\end{tabular}

There are several studies showing that social support is an important factor affecting health promoting behaviors $(18,19)$. Croezen et al. (20) showed that social support was significantly associated with lifestyle. In this cohort study, social support was divided into two categories of positive and negative experiences of support, which both experiences showed significant relationship with lifestyle. Related importance of positive and negative supports in this study showed that positive support can be related to just increase of welfare; while, the negative experiences of support were relevant to the psychological discomfort and there were different mechanisms which affected individuals' health. Ballard found that social and emotional support had relationship with lifestyle and health promotion; the higher scores of support promote better health behaviors (21). But Croezen et al. (22) in another study found that positive perceptions of social support decreased mortality in a 20-years duration, while there was no effect on mortality of the ones with negative perception. Therefore, positive and negative perceptions of support may impact health.

Mirghafourvand et al. (23) found a direct relationship between overall perceived social support and lifestyle behaviors. They also concluded that perceived social support was a strong predictive variable in healthy lifestyle behaviors and intervention in social support should be considered in programs designed to promote health. The factors of education, social support and population index on the prognostic area, was $29.8 \%$ of lifestyle score.

A study in Thailand on females with cervical cancer showed that among cognitive factors, only income and stage of the cancer and total social support were effective on lifestyle. In the current study, the most influential factor was lifestyle behaviors, and with increments by one unit in the level of social support, lifestyle behaviors increased by 0.7 unit (24). In the current study, among other variables, perceived social support was the most influential factor on the lifestyle behaviors.

As shown in the current study, there was a positive and direct relationship between perceived social support in middle aged females with lifestyle, which can be used for interchange in social support and thereinafter change and improvement in lifestyle in this group. The study by Tang et al. (25) on Chinese family caregivers of patients with stroke showed that perceived social support had a direct and positive correlation with such individuals' lifestyle. The study by Taechaboonsermsak et al. (24) on females with cervical cancer and under treatment with radiation therapy evaluated a variety of emotional, information and instrumental supports and reported overall correlation between healthpromoting behavior and support. Ballard (21) showed that social and emotional supports were correlated with promoting lifestyle behaviors; therefore, increase in the level of support leads to the healthier lifestyle behaviors. The results of these studies were consistent with those of the current study.

The results of the current study showed a significant and positive relationship between perceived social support and lifestyles in females. Interventions of social support should be considered in programs for lifestyle improvement in middle-aged females.

It can be concluded that with increasing the social support, health level in such females' increases.

The data in this study were collected at the point in time. The limitation of the study was not the cause of relationship between perceived social support and lifestyle, since the study was cross-sectional. 


\section{Acknowledgments}

This paper is part of approved project of research deputy of Ahvaz Jundishapur University of Medical Sciences under the ethical code of: U - 94033 issued on 23 May, 2015. Authors wish to thank respectable research deputy for supporting the project, and all females who participated in the study.

\section{Footnotes}

Authors' Contribution: Study concept and design: Nahid Javadifar, Atefeh Larki and Mojgan Javadnoori; analysis and interpretation of data: Mohamad Hosein Haghighizadeh, Nahid Javadifar and Atefeh Larki; drafting of the manuscript: Atefeh Larki; critical revision of the manuscript for important intellectual content: Nahid Javadifar and Mojgan Javadnoori; statistical analysis: Mohamad Hosein Haghighizadeh.

Funding/Support: The current study was financially supported by Ahvaz Jundishapur University of Medical Sciences, under the ethical code of: IR.AJUMS.REC1394.90.

\section{References}

1. Noroozi E, Dolatabadi NK, Eslami AA, Hassanzadeh A, Davari S. Knowledge and attitude toward menopause phenomenon among women aged 40-45 years. J Educ Health Promot. 2013;2:25. doi: 10.4103/22779531.112701. [PubMed: 24083275].

2. Ribeiro PS, Jacobsen KH, Mathers CD, Garcia-Moreno C. Priorities for women's health from the Global Burden of Disease study. Int J Gynaecol Obstet. 2008;102(1):82-90. doi: 10.1016/j.ijgo.2008.01.025. [PubMed: 18387613].

3. Zeighami Mohammadi S, Mojdeh F. Correlation between body mass index, body image and depression among referring toHealth Clinic of Hazrat Ali Hospital Health Clinic in Karaj [in Persian]. Modern Care Sci Quarterly Nurs and Mid Fac. 2012;9(1):40-8.

4. Heidari F, Mohammad khan Kermanshahi S. , Vanaki Z, Kazem Nejad A. A survey the effect of planned program of health promotion on stress management in middle -aged women [in Persian]. J Nurs Res. 2011;6(22).

5. Alavimajd H, Sheikhan Z, Ziayi T, Pazande F, Azar M. Sexual satisfaction and associated factors in postmenopausal women [in Persian]. ZanjanUni Med Sci. 2010;18(71):81-9.

6. Kase NG. Impact of hormone therapy for women aged 35 to 65 years, from contraception to hormone replacement. Gend Med. 2009;6 Suppl 1:37-59. doi: 10.1016/j.genm.2009.02.001. [PubMed: 19318218].

7. Kouvonen A, De Vogli R, Stafford M, Shipley MJ, Marmot MG, Cox T, et al. Social support and the likelihood of maintaining and improving levels of physical activity: the Whitehall II Study. Eur J Public Health. 2012;22(4):514-8. doi: 10.1093/eurpub/ckr091. [PubMed: 21750013].

8. Harvey IS, Alexander K. Perceived social support and preventive health behavioral outcomes among older women. J Cross Cult Gerontol. 2012;27(3):275-90. doi: 10.1007/s10823-012-9172-3. [PubMed: 22836374].
9. Tamers S, Okechukwu C, Allen J, Yang M, Stoddard A, Tucker Seeley R. Are social relationships a healthy influence on obesogenic behaviors among racially/ethnically diverse and socioeconomically disadvantaged residents?. Prev Med J. 2013;56(1):70-4. doi: 10.1016/j.ypmed.2012.11.012.

10. Tadayon Najafabadi M, Kalhori H, Javadifar N, Haghighifar MH. As sociation Between Perceived Social Support and Depression in Postmenopausal Women.JJundishapurChronic Dis Care. 2015;4(4):12-7. doi: 10.17795/jjcdc-30126.

11. Rahimi Foroushani A, Estebsari F, Mostafaei D, Eftekhar H, Shojaeizadeh D, Dastoorpour M. The Effect of Health PromotingIntervention on Healthy Lifestyle and SocialSupport in Elders: A Clinical Trial Study. Iran Red Crescent Med J. 2014;16(8):1-10. doi: 10.5812/ircmj.18399.

12. Borhani F, Abszadeh A, Kohan S, Golshan M, Dortajrubary A. Relationship between body mass index and lifestyle among young people in the city of Kerman [in Persian]. J Nurs Rese. 2007;2(6-7):65-72.

13. Tamakoshi A, Tamakoshi K, Lin Y, Yagyu K, Kikuchi S. Healtyh lifestyle and preventable death: Findings from the Japan collaborative cohort study. Prev Med J. 2009;48(5):486-92. doi: 10.1016/j.ypmed.2009.02.017.

14. van Dam RM, Li T, Spiegelman D, Franco OH, Hu FB. Combined impact of lifestyle factors on mortality: prospective cohort study in US women. BMJ. 2008;337:1440. doi: 10.1136/bmj.a1440. [PubMed: 18796495].

15. Weinert C, Brandt PA. Measuring social support with the Personal Resource Questionnaire. West J Nurs Res. 1987;9(4):589-602. [PubMed: 3433744].

16. Rambod M, Rafii F. Perceived social support and quality of life in Iranian hemodialysis patients. J Nurs Scholarsh. 2010;42(3):242-9. doi: 10.1111/j.1547-5069.2010.01353.x. [PubMed: 20738734].

17. Lali M, Abedi A, Kajbaf MB. Validated lifestyle questionnaire LSQ [in Persian]. Psychol Res. 2012;15(1):64-80.

18. Chen MY, James K, Wang EK. Comparison of health-promoting behavior between Taiwanese and American adolescents: a crosssectional questionnaire survey. Int J Nurs Stud. 2007;44(1):59-69. doi 10.1016/j.ijnurstu.2005.11.015. [PubMed: 16386741].

19. Chen CM, Kuo SF, Chou YH, Chen HC. Postpartum Taiwanese women: their postpartum depression, social support and health-promoting lifestyle profiles. J Clin Nurs. 2007;16(8):1550-60. doi: 10.1111/j.13652702.2006.01837.x. [PubMed: 17655544].

20. Croezen HS, Picavet J, Annemien HN, Monique HM, Lisette CP. Do positive or negative experiences of social support relate to current and future health? Results from the Doetinchem Cohort Study. BMC Public Health. 2012;12(65):48-56. doi:10.1186/1471-2458-12-65.

21. Ballard FA. Homeless sheltered women's health promotion behavior Greensboro: University of North Carolina; 2009.

22. Croezen S, Haveman-Nies A, Picavet HS, Smid EA, de Groot CP, Van't Veer P, et al. Positive and negative experiences of social support and long-term mortality among middle-aged Dutch people. Am J Epidemiol. 2010;172(2):173-9. doi: 10.1093/aje/kwq095. [PubMed 20543032].

23. Mirghafourvand M, Baheiraei A, Nedjat $\mathrm{SH}$, Mohammadi E, Mohammadi S, Charandabi A. A population-based study of health-promoting behaviors and their predictors in Iranian women of reproductive age. J Health Promot Int. 2014;13:1-9. doi: 10.1093/heapro/dat086.

24. Taechaboonsermsak P, Kaewkungwal J, Singhasivanon P, Fungladda $\mathrm{W}$, Wilailak S. Causal relationship between health promoting behavior and quality of life in cervical cancer patients undergoing radiotherapy. Southeast Asian J Trop Med Public Health. 2005;36(6):1568-75. [PubMed: 16610663].

25. Tang Y, Chen SP. Health promoting behaviors in Chinese family caregivers of patients with stroke. Health Promot Int. 2002;17:329-39. doi: 10.1093/heapro/17.4.329. 
Table 1. Sociodemographic Profile of Subjects

\begin{tabular}{|c|c|c|}
\hline Demographic Variables & & No. (\%) \\
\hline \multirow{4}{*}{ Age } & $40-45$ & $359(51.3)$ \\
\hline & $46-50$ & $160(22.9)$ \\
\hline & $51-55$ & $90(12.9)$ \\
\hline & $56-60$ & $91(13)$ \\
\hline \multirow{4}{*}{ Age of husband } & $\leq 40$ & $63(9)$ \\
\hline & $41-50$ & $300(42.9)$ \\
\hline & $51-60$ & $170(24.3)$ \\
\hline & $\leq 61$ & $63(9)$ \\
\hline \multirow{6}{*}{ Number of family members (family dimension) } & Living alone & $18(2.6)$ \\
\hline & 2 people & $38(5.4)$ \\
\hline & 3 people & $99(14.1)$ \\
\hline & 4 people & $175(25)$ \\
\hline & 5 people & $168(24)$ \\
\hline & More than 5 & $202(28.8)$ \\
\hline \multirow{3}{*}{ Education level } & Elementary & $244(34.9)$ \\
\hline & Secondary school-diploma & $343(49)$ \\
\hline & Academic & $113(16.1)$ \\
\hline \multirow{3}{*}{ Education of husband } & Elementary & $173(24.7)$ \\
\hline & Secondary school-diploma & $301(43)$ \\
\hline & Academic & $120(17.1)$ \\
\hline \multirow{3}{*}{ Economic situation } & Poor & $158(22.6)$ \\
\hline & Middle & $404(57.7)$ \\
\hline & Good & $138(19.7)$ \\
\hline \multirow{5}{*}{ Job } & Housewife & $507(74.4)$ \\
\hline & Employee & $99(14.1)$ \\
\hline & Self-employed & $56(8)$ \\
\hline & Retired & $13(1.9)$ \\
\hline & Other & $25(3.6)$ \\
\hline \multirow{5}{*}{ Husband's job } & Unemployed & $43(6.1)$ \\
\hline & Employee & $184(26.3)$ \\
\hline & Self-employed & $224(32)$ \\
\hline & Retired & $95(13.6)$ \\
\hline & Other & $50(7.1)$ \\
\hline \multirow{4}{*}{ Ethnicity } & Arab & $314(44.9)$ \\
\hline & Lor & $165(23.6)$ \\
\hline & Persian & $157(22.4)$ \\
\hline & Other & $64(9.1)$ \\
\hline \multirow{3}{*}{ Marital status } & single & $41(5.9)$ \\
\hline & married & $594(84.9)$ \\
\hline & Widow/divorced & $65(9.3)$ \\
\hline \multirow{8}{*}{ Family structure } & Independent & $520(74.3)$ \\
\hline & Dependent & $180(25.7)$ \\
\hline & Living with son family & $50(7.1)$ \\
\hline & Living with daughter family & $20(2.9)$ \\
\hline & Living with mother or father in law & $48(6.9)$ \\
\hline & Living with other relatives & $54(7.7)$ \\
\hline & Living with friends & $8(1.1)$ \\
\hline & Healthy & $469(67)$ \\
\hline
\end{tabular}

Health status 


\begin{tabular}{l|c|c}
\multirow{5}{*}{ Main supporter } & Recovering & 222(31.7) \\
\cline { 2 - 3 } & Ill & \multicolumn{2}{|c}{$9(1.3)$} \\
\hline \multirow{4}{*}{} & Husband & $306(43.3)$ \\
\cline { 2 - 3 } & Parents & $80(11.4)$ \\
\cline { 2 - 3 } & Children & $121(17.3)$ \\
\cline { 2 - 3 } & Friends & $29(4.1)$ \\
\cline { 2 - 3 } & Other relatives & $106(15.1)$ \\
\cline { 2 - 3 } & Governmental organizations & $27(3.9)$ \\
\hline
\end{tabular}

